\title{
MULTI-OBJECTIVE CONTRACTOR'S RANKING BY APPLYING THE MOORA METHOD
}

\author{
Willem Karel M. Brauers ${ }^{1}$, Edmundas Kazimieras Zavadskas ${ }^{2}$, Zenonas Turskis ${ }^{3}$, Tatjana Vilutiene் ${ }^{4}$ \\ ${ }^{1}$ University of Antwerpen, Birontlaan, 97, B2600 Berchem Antwerpen, Belgium \\ E-mail:willem.brauers@ua.ac.be \\ 2,3,4Vilnius Gediminas Technical University, Saulètekio al. 11, LT-10223 Vilnius, Lithuania \\ E-mails: ${ }^{2}$ edmundas.zavadskas@adm.vgtu.lt; ${ }^{3}$ zenonas.turskis@st.vgtu.lt; ${ }^{4}$ tatjana.vilutiene@st.vgtu.lt
}

Received 18 November 2007; accepted 15 July 2008

\begin{abstract}
Construction, taking off, maintenance and facilities management of a building is a typical example of consumer sovereignty: the new owner likes to have a reasonable price to pay, to have confidence in the contractor, to know about the duration of the works, the service after completion and the quality of the work. On the other side the contractor has his objectives too, like the satisfaction of the client, diminishing of external costs and annoyances and the management cost per employee as low as possible. In other words it concerns a problem of multi-objectives. Therefore a final ranking will show the best performing contractor from the point of view of the clients but also from the point of view of the contractors themselves. The MOORA method based on ratio analysis and dimensionless measurement will accomplish the job of ranking the contractors in a non-subjective way. As an application the largest maintenance contractors of dwellings in Vilnius, capital of Lithuania, were approached.
\end{abstract}

Keywords: contractor, decision making, multi-objectives, alternatives, sampling, ratio analysis, dimensionless measures, ranking and optimization, the MOORA method.

\section{Introduction}

The effectiveness of construction and maintenance depends on many micro- and macro-environmental factors. Therefore, planning and successful implementation of construction and maintenance activities require the evaluation of the capabilities of the participants of those processes and the influence of the environment on their effectiveness. The participants of the process can perform their functions efficiently only taking into consideration the changing environment, pursuing the best coordination of actions, raising the quality of services and meeting the needs of dwelling owners. Effectiveness is hereby perceived as the process of providing building maintenance services, which results in ultimate implementation of the goals of the interested groups participating in the process. The effectiveness of any process is assessed in terms of objectives, which vary depending on the problem concerned and the particular goals of the interested groups. The utmost effectiveness is often associated with the maximum gain from a specific activity. The more numerous and significant aims are achieved, the higher is the gain and the effectiveness of the activity. The effectiveness of decision making will depend on the goals of all interested groups, participating in the process and with regard to the impact of the microand macro-environmental factors. Contractors cannot correct or change aforementioned factors, but they can realize their impact and evaluate it during the implementation of different projects, herewith successfully organizing their current and future activities. The term 'effectiveness' can be interpreted differently; therefore one has to evaluate all the needs of the participants of the process. Modelling and multi-objective analysis allow us to find a way to meet the goals of the participants of different process and to choose an optimal solution as well as the ways to implement it.

Construction projects are one-off endeavours with many unique features such as long period, complicated processes, changing environment. As construction projects become more complex, the need for evaluating contractor performance becomes more crucial. Organizational and technological complexity of construction projects generates enormous risks. The selection of a qualified contractor gives confidence to the stakehold- 
er that the selected contractor can achieve the project goals. However, the importance of contractor selection is mostly underestimated and neglected in construction (Ng and Wan 2005). It is hard to analyze many tradeoffs involved in decision making, especially in times with so many uncertainties presented by environmental considerations. Insufficient time for execution, complicated procedures or poor information channels may be the reasons of problems in the selection of contractors (Shiau et al. 2002). Contractor evaluation has been recognized as a particularly complex task due to its ambiguity and difficult formalisation (Shiau et al. 2002; Tseng and Lin 2002). There have been no generalized sets of rules for the evaluation process.

Contractor selection deals with risk and risk management. Companies working in construction market face more demanding business environment that is usually non-stable. For instance, Lithuanian construction market is influenced by political, social, economic, technological and other transformations currently undergoing in Eastern and Central Europe (Ginevičius and Korsakienè 2005). Implementing the construction projects, it must be first of all considered what risks should be countered with measures and how costly these measures are (Schieg 2006). Zou et al. (2007) state that the risks in construction projects can be classified as follows: cost overrun, time delay, quality, safety, environmental sustainability and funding, contractors' poor management ability, contractors' difficulty in reimbursement, poor competency of labourers, not buying insurance for major equipments and employees, inadequate safety measures or unsafe operations, lack of readily available utilities on site, prosecution due to unlawful disposal of construction waste and serious air and water pollution due to construction activities, suppliers' incompetency to deliver materials on time.

Many construction contracts are awarded to the lowest bidder. An offered bid price is undoubtedly an important factor in choosing a contractor, but there are many other important ones playing a vital role in project implementation that have to be incorporated in the contractor's evaluation process. The contractor pre-qualification process involves the establishment of a standard for measuring and assessing the capabilities of potential contractors ( $\mathrm{Ng}$ et al. 1999). The information used for the assessment of parameters for prequalification should fall into several groups (Hatush and Skitmore 1997). Jaselskis and Russel (1992) have identified commonly used attributes for pre-qualification and bid evaluation and have proposed methodologies for contractor selection. Zavadskas and Kaklaus- kas (1996) selected 25 attributes of contractor selection and applied COPRAS method to contractor selection. Hatush and Skitmore (1998) have initiated the use of systematic multi-attribute decision analysis techniques for contractor selection and bid evaluation based on additive multi-attribute utility function model. Banaitiene and Banaitis (2006) performed an analysis of criteria for contractors' evaluation. Dikmen et al. (2007) after conducting a thorough research, selected 44 candidate factors affecting the bid mark-up decisions as factors having potential impact on bid mark-up size for a project. The factors are divided into 4 groups, namely: general features about company and project, risk factors, opportunity factors and competition factors.

An extensive literature review by the researchers revealed that the most acceptable contractor's pre-qualification attributes are financial stability, management and technical ability, contractor's experience, contractor's performance, resources, quality management and health and safety concerns. Therefore, the contractor's attributes corresponding to these attributes should be evaluated.

Many researches (Zavadskas and Kaklauskas 1996, 2007; Ginevičius and Vaitkūnaitè 2006; Zavadskas and Vilutiene 2006) have pointed out that in construction it is essential to be able to take into account the impacts of cultural, social, moral, legislative, demographic, economic, environmental, governmental and technological change, as well as changes in the business world on international, national, regional and local real estate markets. Evaluation of contractors based on multi-attributes is becoming more popular and is, in essence, largely dependent on the uncertainty inherent in the nature of construction projects and subjective judgment of decision makers.

Multi-attribute decision making is defined by processes that involve designing the best alternative with the most attractive attributes, and that involves the selection of the optimal alternative, handled via preference models (Sage 1977; Hwang and Yoon 1981). Multi-attribute decision making can be classified as follows:

a) Multi-attribute decision making (MADM) for the sorting or the ranking of alternatives according to several attributes and

b) Multi-objective decision making (MODM), for driving a vector optimization-based design process to a solution (Colson and Bruyn 1989).

Multi-attribute methods can be classified by the type of initial information (deterministic, stochastic, fuzzy set theory methods) or by the number of decisionmakers (one or group). Scientists classify deterministic MADM methods differently. Lin and Wu (2007) 
presented classification of the methodology which can be used for qualitative and quantitative methods aimed at technology management.

To select contractors Topcu (2004) used Analytical Hierarchy Process methods and proposed a multi-attribute decision model based on time, price and quality attributes evaluation for eligible contractor selection. Skibniewski and Chan (1992) applied this method to the selection of rational construction technology. Mitkus and Trinkuniene (2006) analyzed three models of multi-attribute systems of construction contraction agreements, whereas in 2007 they (Mitkus and Trinkuniene 2007) suggested to use analytic hierarchical model (AHP) for structural evaluation of construction contracts.

Keršulienė (2007) proposed analysis model for construction process parties during dispute settlement. She stated that with the use of optimism and asymmetric information models it is possible to determine the most economically advantageous behavioural pattern for both parties.

Selection of a contractor is an important issue in construction field (Zagorskas and Turskis 2006; Turskis et al. 2006; Zavadskas and Vilutiene 2006) for the success or failure of a project is usually influenced by the quality of contractor. The researches listed above had significantly improved the contractor selection process in the construction industry. However, some of the proposed methods and approaches could be complex and difficult to apply in practice. The construction industry needs simple but effective methods in contractor selection process due to the limited time intervals of the bidding periods. For these and many other reasons, selection of a construction contractor requires the contractor selection model that should be able to meet the critical characteristics of the pre-qualification:

- a multi-attribute problem.

- risks inherited from different decision maker's opinions.

- noisy and uncertain date given by different contractors.

- subjective judgment made by decision makers.

- non-linear relationships between contractor's attributes and their corresponding pre-qualification decisions.

- to deal with qualitative as well as quantitative data.

It should be noted that the stakeholders must adjust the attributes depending on the demand of each project. The critical point is that the selected attributes should have a direct effect on performance. In addition, the selected evaluation attributes should be also based on the measurement culture of the stakeholder.
Many objectives have to be considered for selecting a qualified contractor on a competitive basis. Once being convinced about multi-objectives, Multi-Objective Decision Making research is divided into the following groups (Thousands and thousands of publications on each of these methods are edited. Therefore, only the first pioneering publication of each method is mentioned):

1) An Ordinal Preference. The method of correlation of ranks, consisting of totalizing ranks, is the first method to be considered. Rank correlation was introduced first by psychologists such as Spearman (1904, 1906 and 1910) and later taken over by the statistician Kendall in 1948. The Lexicographic Method belongs also to this group (Holmes 1971).

2) Additive Weighting with the sum of weights equal to one (Churchman et al. 1954, 1957).

3) Methods based on quantitative measurement but using a few criteria to compare the alternatives pairwise. Schärlig (1985) calls them partial aggregation methods. This group consists of preference comparison methods like the group around Electre (Roy et al. 1966) and the Indifference Method (Brauers 1977 b).

4) Methods based on initial qualitative assessment, the results of which take a quantitative form later. This group consists mainly of analytic hierarchy methods (Saaty 1988), as well as the methods based on fuzzy sets (Zimmermann 1978).

5) Methods based a) on a Reference Point (Minkowsky 1896; Karlin and Studden 1966) in the Reference Point Method such as used in TOPSIS (Hwang and Yoon 1981), COPRAS (Zavadskas and Kaklauskas 1996) or b) on a Goal like in Goal Programming (Lee 1972).

6) Bridgman discussed dimensionless measures already in 1922. Multi-objectives researchers discovered dimensionless measures as a welcome gift in order to whither away with the cumbersome normalization necessary for the different units of the different objectives.

First, the Multiplicative Form is based on dimensionless measures. Miller and Starr (1969) demonstrated ratios that do not change if single-dollar units are transformed to million-dollar units even when attributes are raised to powers. The Multiplicative Form for Multiple Objectives was further elaborated by Schärlig (1985) and Brauers (1997a, 1999, 2002, 2004).

Second, ratio analysis responds to dimensionless measures analysis, which is applied in MOORA (Multi-Objective Optimization by Ratio Analysis). MOORA was introduced for the first time by Brauers and Zavadskas 
in "Control and Cybernetics" in 2006, after introducing its first part, the ratio system, in Brauers (2004).

Given these different approaches preference is given to an approach satisfying the following conditions:

- Cardinal and not ordinal, given the weak points of an ordinal approach as demonstrated by Arrow (1974) and Brauers (2007);

- All objectives should be considered and respected as much as possible;

- All stakeholders are involved and not only the decision maker or a group of decision makers. All stakeholders mean everybody interested in a certain issue;

- All interrelations between objectives and alternatives are looked upon at the same time instead of pairwise considerations;

- Only discrete cases facing a set of a limited number of alternatives are considered, whereas continuous cases concern alternatives generated out of a set of continuous and numerous alternatives;

- As non-subjective as possible: no normalization by subjective weights but by non-subjective dimensionless measures.

For all these reasons we selected MOORA.

\section{The MOORA method}

The method starts with a matrix of responses of different alternatives on different objectives:

$$
X=\left[\begin{array}{ccccc}
x_{11} & \cdots & x_{1 i} & \cdots & x_{1 n} \\
\vdots & \ddots & \vdots & . & \vdots \\
x_{j 1} & \cdots & x_{j i} & \cdots & x_{j n} \\
\vdots & . & \vdots & \ddots & \vdots \\
x_{m 1} & \cdots & x_{m i} & \cdots & x_{m n}
\end{array}\right],
$$

where: $x_{i j}$ - the response of alternative $j$ on objective or attribute $i ; i=1,2, \ldots, n-$ is the number of the objectives or the attributes; $j=1,2, \ldots, m-$ is the number of the alternatives.

In order to define objectives, we have to focus on the notion of Attribute. Keeney and Raiffa (1993) present the example of the objective 'reduce sulfur dioxide emissions' to be measured by the attribute 'tons of sulfur dioxide emitted per year'. An objective and a correspondent attribute always go together. Consequently, when the text mentions objective, the correspondent attribute is also meant.

The MOORA Method consists of two components: (a) the ratio system and (b) the reference point approach.

\subsection{The Ratio System as a part of MOORA}

We go for a ratio system in which each response of an alternative on an objective is compared to a denominator which is a representative for all alternatives concerning that objective (Brauers and Zavadskas 2006). Authors proved that for this denominator the best choice is the square root of the sum of squares of each alternative per objective:

$$
x_{i j}^{*}=\frac{x_{i j}}{\sqrt{\sum_{j=1}^{m} x_{i j}^{2}}},
$$

where: $x_{i j}$ response of alternative $j$ on objective $i ; j=$ $1,2, \ldots, m ; m$ - the number of alternatives; $i=1,2$, $\ldots, n ; n-$ the number of objectives; $x_{i j}^{*}$ - a dimensionless number representing the normalized response of alternative $j$ on objective $i$.

Dimensionless Numbers, having no specific unit of measurement, are obtained for instance by deduction, multiplication or division. The normalized responses of the alternatives on the objectives belong to the interval $[0 ; 1]$. However, sometimes the interval could be $[-1 ; 1]$. Indeed, for instance, in the case of productivity growth some sectors, regions or countries may show a decrease instead of increase in productivity, i.e. a negative dimensionless number.

For example, instead of a normal increase in productivity growth a decrease remains possible. At this moment, the interval becomes $[-1,1]$. Let us consider an example of productivity which has to increase (positive). Consequently, we look after productivity maximization, e.g. in European and American countries. What if the opposite does occur? For instance, let us analyse the original transition from the USSR to Russia.

Contrary to the other European countries, its productivity decreased. It means that in formula (2) the numerator for Russia would be negative with the whole ratio becoming negative. Consequently, we get the interval $[-1 ;+1]$ instead of $[0 ; 1]$. For optimization, these responses are added in case of maximization and subtracted in case of minimization:

$$
y_{j}^{*}=\sum_{i=1}^{i=g} x_{i j}^{*}-\sum_{i=g+1}^{i=n} x_{i j}^{*},
$$

where: $i=1,2, \ldots, g$ - the objectives to be maximized; $i=g+1, g+2, \ldots, n-$ the objectives to be minimized; $y_{j}^{*}-$ the normalized assessment of alternative $j$ with respect to all objectives.

An ordinal ranking of the $y_{j}^{*}$ shows the final preference. Indeed, cardinal scales can be compared in an ordi- 
nal ranking, according to Arrow (1974): 'Obviously, a cardinal utility implies an ordinal preference but not vice versa'.

\subsection{The Reference Point Approach as a part of MOORA}

Reference Point Theory is based on the ratios found in formula (2) whereby a Maximal Objective Reference Point is also deduced. The Maximal Objective Reference Point approach is called realistic and nonsubjective when the co-ordinates $\left(r_{\mathrm{i}}\right)$ selected for the reference point are realized in one of the candidate alternatives. For example, we have three alternatives. The alternatives are described as follows: A $(10 ; 100)$, B $(100 ; 20)$ and C $(50 ; 50)$. In this case the maximal objective reference point $\boldsymbol{R}_{\boldsymbol{m}}$ results in $(100 ; 100)$. The Maximal Objective Vector is self-evident if the alternatives are well defined as for the projects in the area of Project Analysis and Planning.

Having given the dimensionless number representing the normalized response of alternative $j$ on objective $i$, i.e. $x_{i j}^{*}$ in formula (2), we come to:

$$
\left(r_{i}-x_{i j}^{*}\right)
$$

where: $j=1,2, \ldots, m ; m$ - the number of alternatives; $i=1,2, \ldots n ; n-$ the number of objectives; $r_{i}-$ the $i^{t h}$ co-ordinate of the reference point; $x_{i j}^{*}$ - the normalized attribute $i$ of alternative $j$.

This matrix is subject to the Min-Max Metric of Tchebycheff (Karlin and Studden 1966; Brauers and Zavadskas 2006):

$$
\min _{j} \max _{i}\left(r_{i}-x_{i j}^{*}\right)
$$

Bauers and Zavadskas (2006) showed Min-Max metric is the best choice between all the possible metrics of reference point theory.

\subsection{The Importance given to an Objective}

The normalized responses of the alternatives on the objectives belong to the interval $[0 ; 1]$ (see formula 2 ). Nevertheless, it may turn out to be necessary to stress that some objectives are more important than the others. In order to give more importance to an objective, it could be multiplied with a Significance Coefficient.

$$
\bar{y}_{j}^{*}=\sum_{i=1}^{i=g} s_{i} x_{i j}^{*}-\sum_{i=g+1}^{i=n} s_{i} x_{i j}^{*},
$$

where: $j=1,2, \ldots, m ; m$ - the number of alternatives; $i=1,2, \ldots n ; n$ - the number of objectives; $g-$ the number of objectives to be minimized; $n-g-$ the number of objectives to be maximized; $s_{i}$ - the significance coefficient of objective $i ; \bar{y}_{j}^{*}-$ the normalized assessment of alternative $j$ with respect to all objectives with significance coefficients; $x_{i j}^{*}-$ a dimensionless number representing the normalized response of alternative $j$ on objective $i$.

The Attribution of Sub-Objectives represents still another solution. Let us consider an example of purchasing fighter planes (Brauers 2002). From an economic point of view, apart from military effectiveness the objectives concerning the fighter planes are threefold price, employment and balance of payments. In order to give more importance to military defence, effectiveness is broken down in, for instance, the maximum speed, the power of the engines and the maximum range of the plane. Anyway, the Attribution Method is more refined than a significance coefficient method. The attribution method succeeds in characterizing an objective better.

\section{Application of the proposed method for evaluating contractor's alternatives}

Objectives are determined on the basis of the opportunities for the contractors and of the wishes of the customers.

The largest maintenance contractors of dwellings in Vilnius, the capital of Lithuania, were approached, of which 15 agreed to fix and estimate their main objectives, namely 9 objectives as given in Table 1 (Dr Tatjana Vilutiene took care of the field work). The full names of the contractors are not provided for the sake of confidentiality.

The nature of the construction industry involves that the total number of the minima is mostly larger than the total number of the maxima.

Contractor's rating is performed according to the attributes (Table 2).

From information of the Dwelling Owners Association, a panel of 30 owners of dwellings chosen at random agreed with these 9 objectives, but they increased the objectives with 11 other ones (These additional objectives were: quality standard of management services, quality of maintenance of common property, work organization, the effectiveness of information use, certification of company, range of services, reliability of company, company reputation, staff qualification and past experience, communication skills, geographical market restrictions.). However these additional objectives were only expressed in qualitative points, showed some overlapping and after their rating represented only $25.9 \%$ importance of the total. If these opinions are only taken as indicative these qualitative objectives can be dropped. 
Table 1. Main attributes and objectives of maintenance contractors of dwellings in Vilnius

\begin{tabular}{|c|c|c|c|c|}
\hline No. & Attributes & Units of measurement & $\max / \min$ & \\
\hline 6. & Length of time in maintenance business (experience) & years & $\max$ & $x_{1}$ \\
\hline 7. & Market share for each contractor & $\%$ & $\max$ & $x_{2}$ \\
\hline 8. & Number of projects per executive & units/person & $\max$ & $x_{3}$ \\
\hline 9. & Evaluation of management $\operatorname{cost}\left(\mathrm{C}_{\min } / \mathrm{C}_{\mathrm{p}}\right)^{*}$ & - & $\max$ & $x_{4}$ \\
\hline 1. & Cost of building management & $\mathrm{Lt}^{*} / \mathrm{m}^{2}$ & $\min$ & $x_{5}$ \\
\hline 2. & Cost of common assets management & $\mathrm{Lt} / \mathrm{m}^{2}$ & $\min$ & $x_{6}$ \\
\hline 3. & HVAC system maintenance cost (mean) & $\mathrm{Lt} / \mathrm{m}^{2}$ & $\min$ & $x_{7}$ \\
\hline 4. & Courtyard territory cleaning (in summer) & $\mathrm{Lt} / \mathrm{m}^{2}$ & $\min$ & $x_{8}$ \\
\hline 5. & Total service cost & $\mathrm{Lt} / \mathrm{m}^{2}$ & $\min$ & $x_{9}$ \\
\hline
\end{tabular}

*The management cost evaluates the cost competitiveness of a contractor:

$\frac{C_{\min }}{C_{p}} \leq 1$, where: $C_{\min }-$ the minimal cost in all offerings, $C_{p}-$ the cost offered by the contractor considered.

Appendix A provides more details on the attributes.

Table2. Initial decision making matrix of 15 contractors of dwellings in Vilnius

\begin{tabular}{|c|c|c|c|c|c|c|c|c|c|}
\hline \multirow{2}{*}{ Alternatives $\downarrow$} & \multicolumn{9}{|c|}{ Objectives $\leftrightarrow$} \\
\hline & $x_{1}$ & $x_{2}$ & $x_{3}$ & $x_{4}$ & $x_{5}$ & $x_{6}$ & $x_{7}$ & $x_{8}$ & $x_{9}$ \\
\hline$a_{1}$ & 12 & 11.75 & 4.6 & 0.83 & 0.064 & 0.11 & 0.18 & 0.31 & 0.67 \\
\hline$a_{2}$ & 3 & 0.39 & 0.33 & 0.885 & 0.06 & 0.14 & 0.37 & 0.12 & 0.5 \\
\hline$a_{3}$ & 12 & 5.25 & 1.47 & 0.935 & 0.057 & 0.11 & 0.18 & 0.15 & 0.69 \\
\hline$a_{4}$ & 12 & 7.09 & 2.78 & 0.912 & 0.058 & 0.12 & 0.09 & 0.15 & 0.57 \\
\hline$a_{5}$ & 12 & 5.56 & 1.39 & 0.912 & 0.058 & 0.1 & 0.18 & 0.2 & 0.45 \\
\hline$a_{6}$ & 13 & 26.62 & 5.67 & 0.746 & 0.071 & 0.3 & 0.18 & 0.26 & 0.82 \\
\hline$a_{7}$ & 5 & 2.82 & 1.2 & 0.483 & 0.11 & 0.14 & 0.18 & 0.12 & 0.55 \\
\hline$a_{8}$ & 11 & 9.48 & 3.03 & 0.916 & 0.058 & 0.18 & 0.37 & 0.19 & 0.61 \\
\hline$a_{9}$ & 11 & 2.23 & 0.76 & 1 & 0.053 & 0.14 & 0.16 & 0.23 & 0.8 \\
\hline$a_{10}$ & 11 & 13.47 & 9.05 & 0.746 & 0.071 & 0.26 & 0.29 & 0.23 & 0.73 \\
\hline$a_{11}$ & 4 & 4.7 & 1.5 & 0.443 & 0.12 & 0.2 & 0.09 & 0.2 & 0.81 \\
\hline$a_{12}$ & 12 & 2.35 & 0.86 & 0.746 & 0.071 & 0.28 & 0.18 & 0.28 & 0.73 \\
\hline$a_{13}$ & 8 & 5.6 & 3.25 & 0.681 & 0.078 & 0.2 & 0.18 & 0.3 & 0.76 \\
\hline$a_{14}$ & 11 & 2.66 & 1.7 & 0.948 & 0.056 & 0.14 & 0.18 & 0.12 & 0.5 \\
\hline$a_{15}$ & 3 & 0.04 & 0.03 & 0.531 & 0.12 & 0.14 & 0.09 & 0.21 & 0.56 \\
\hline
\end{tabular}

Is the owner's information useful to allot significance coefficients? Therefore the sample is not enough representative.

Indeed, a significance coefficient of importance was not possible to give to the 9 objectives as 30 interviews even chosen at random mean a confidence level of only: standard error $s_{e}=\sqrt{\frac{p q}{n}}=\sqrt{\frac{0.25}{30}}=0.09$, which means $9 \%$ under or $9 \%$ above the real percentage. Economics generally accept 100 interviews with a standard error of: $s_{e}=\sqrt{\frac{p q}{n}}=\sqrt{\frac{0.25}{100}}=0.05$, which means $5 \%$ under or $5 \%$ above the real percentage ( $p=$ expected probability; $q=1-p$; in a symmetric distribution: $q=p$.
Instead of attributing significance coefficients the contractors and the small group of owners preferred the Attribution of Sub-Objectives. Indeed, five objectives concern minimization of costs (Effectiveness). Even, the last maximization forms a cost consideration. Furthermore, one objective is related to Experience, as measured by length of time in maintenance business, one to Size as measured by market share and finally one objective measures Effectiveness as expressed by number of projects per executive.

Table 3 presents the results of the calculation process of MOORA. Appendix B gives the details of this calculation. 
Table 3. Ranking of the 15 contractors by the two parts of MOORA

\begin{tabular}{|c|c|c|}
\hline \multirow[t]{2}{*}{ Contractors } & \multicolumn{2}{|c|}{ MOORA } \\
\hline & Square root part & Reference Point part \\
\hline$a_{1}$ & 4 & 3 \\
\hline$a_{2}$ & 12 & 14 \\
\hline$a_{3}$ & 6 & 8 \\
\hline$a_{4}$ & 3 & 5 \\
\hline$a_{5}$ & 5 & 7 \\
\hline$a_{6}$ & 1 & 1 \\
\hline$a_{7}$ & 11 & 10 \\
\hline$a_{8}$ & 8 & 4 \\
\hline$a_{9}$ & 9 & 13 \\
\hline$a_{10}$ & 2 & 2 \\
\hline$a_{11}$ & 14 & 9 \\
\hline$a_{12}$ & 13 & 12 \\
\hline$a_{13}$ & 10 & 6 \\
\hline$a_{14}$ & 7 & 11 \\
\hline$a_{15}$ & 15 & 15 \\
\hline
\end{tabular}

Both parts of MOORA method rank in the same way the first three positions after the quality of the contractors. In this way a double check is made on the results as shown in the following Table 4.

Table 4. No discussion on the ranking of the first three positions

\begin{tabular}{ccc}
\hline \multirow{2}{*}{ Contractors } & \multicolumn{2}{c}{ MOORA } \\
\cline { 2 - 3 } & Square root part & Reference Point part \\
\hline $\boldsymbol{a}_{\boldsymbol{6}}$ & 1 & 1 \\
\hline $\boldsymbol{a}_{\boldsymbol{1 0}}$ & 2 & 2 \\
\hline $\boldsymbol{a}_{\boldsymbol{1}}$ & 4 & 3 \\
\hline
\end{tabular}

According to the results of Table 3, we can find the priority between the contractors ( $\mathbf{P}$ - preferred to):

$a_{6} \mathrm{P} a_{10} \mathrm{P} a_{4} \mathrm{P} a_{1} \mathrm{P} a_{5} \mathrm{P} a_{3} \mathrm{P} a_{14} \mathrm{P} a_{8} \mathrm{P} a_{9} \mathrm{P} a_{13} \mathrm{P} a_{7}$ $\mathbf{P} a_{2} \mathbf{P} a_{12} \mathbf{P} a_{11} \mathbf{P} a_{15}$ (Square root part) and $a_{6} \mathrm{P} a_{10} \mathrm{P} a_{1} \mathrm{P} a_{8} \mathrm{P} a_{4} \mathrm{P} a_{13} \mathrm{P} a_{5} \mathrm{P} a_{3} \mathrm{P} a_{11} \mathrm{P} a_{7} \mathrm{P} a_{14}$ $\mathbf{P} a_{12} \mathbf{P} a_{9} \mathbf{P} a_{2} \mathbf{P} a_{15}$ (Reference Point part).

In other words three contractors are classified in a good order, $a_{4}$ has still to be mentioned with its $3^{\text {rd }}$ and $5^{\text {th }}$ ranking position, whereas contractor $a_{15}$ is the very last one. The other 10 contractors are ranked low but it is unclear in what position.

Contractor 6 is ranked first for size and experience and second for effectiveness. Contractor 10 is ranked first for effectiveness and second for size. Contractor 1 together with contractor 4 are ranked second for experience. All these strong contractors are not so good in effectiveness (costs), which seems rather unusual. On the other side, size of the enterprise seems to be very important. In this way the comments that from the beginning no small firms were considered are without any value.

Concerning the use of the Maximal Objective Reference Point Approach as a part of MOORA some reserves can be made in connection with consumer sovereignty of the house owners. Consumer sovereignty is measured with the community indifference manifold map of these house owners (Brauers 2004). Given its definition the Maximal Objective Reference Point is pushed in the non-allowed non-convex zone of the highest community indifference manifold (Brauers and Zavadskas 2006). Therefore an aspiration objective vector can be preferred, which moderates the aspirations by choosing smaller co-ordinates than in the maximal objective vector and consequently can be situated in the convex zone of the highest community indifference manifold. Indeed stakeholders may be more moderate in their expectations. The co-ordinates $q_{i}$ of an Aspiration Objective Vector are formed as: $q_{i} \leq$ $r_{i} \cdot\left(r_{i}-q_{i}\right)$ being a subjective element we do not like to introduce subjectivity in that way again. Instead: 1) a test shows that the Min-Max Metric of Tchebycheff delivers points inside the convex zone of the highest community indifference manifold (Brauers 2008). 2) Given the higher number of minimizations compared to the number of maximizations in the example a second argument exists to assume that the reference point is located in the convex zone.

\section{Conclusions}

Different approaches exist in Multi -Objective Decision Making research. Given these different approaches preference is given to an approach satisfying the following conditions:

1) cardinal and not ordinal, given the weak points of an ordinal approach;

2) all objectives should be considered as much as possible;

3) all stakeholders are involved and not only the decision maker or a group of decision makers. All stakeholders mean everybody interested in a certain issue;

4) all interrelations between objectives and alternatives are looked upon at the same moment instead of pairwise considerations;

5) only discrete cases facing a set of a limited number of alternatives are considered, whereas continuous cases concern alternatives generated out of a set of continuous and numerous alternatives;

6) as non-subjective as possible: no normalization by subjective weights but by non-subjective dimensionless measures.

For all these reasons we selected MOORA. 
The MOORA Method, based on dimensionless measures, consists of two parts: the ratio system and the reference point approach, each controlling each other. MOORA was applied for the choice between the 15 main contractors of dwellings to satisfy the wishes of the owners of dwellings in the city of Vilnius, the capital of Lithuania.

The MOORA method came to the following results: three contractors take the first three positions. A fourth one has still to be mentioned with its favourable ranking position whereas one contractor is classified as the very last one. The other 10 contractors are ranked low but it is unclear in what position. The best contractors are not the best in effectiveness (costs), which seems rather unusual. On the other side, the size of the enterprise seems to be very important. In this way the comments that from the beginning no small firms were considered are without any value.

Even more, for contractors and their clients' firm quality as measured by size, experience and effectiveness seems to dominate the cost price of a dwelling. A new research based on the newest data, larger samples and a larger number of quantified objectives may verify this rather unexpected outcome.

\section{Appendix A}

Cost of building management - calculated average value of all buildings' management cost. Building management activities cover all administrative activities necessary to manage building maintenance operations: monthly reports, budgeting, cost calculations, hiring the subcontractors, control and coordination of all subcontractors involved in building maintenance process, procurement, repair organization, preparation of procedures, manuals and instructions, etc.

Cost of common assets' management - common assets mean all building equipment, structures, land and internal spaces, which are the common property of building owners.

HVAC system maintenance cost (average value) HVAC mean heating, ventilating, and air conditioning systems, which are installed in building. In questionnaires this criterion was marked as one of the most important criteria for building users.

Courtyard territory cleaning (in summer) - an environmental issue is signifying the importance of healthy surroundings. In questionnaires this criterion was marked as one of the most important criteria for building users.
Total service cost - covers the cost of building management, cost of common assets' management, HVAC system maintenance cost, courtyard territory cleaning (in summer) cost, cost of territory cleaning in winter, cost of cleaning of internal surfaces, cost of repairs and cost of other necessary services.

Length of time in maintenance business (experience) - the lifetime of company in facilities management field from establishment.

Market share for each contractor (in Vilnius) - in strategic management and marketing, is the percentage or proportion of the total available market or market segment that is being serviced by a company. It can be expressed as a company's sales revenue (from that market) divided by the total sales revenue available in that market. It can also be expressed as a company's unit sales volume (in a market) divided by the total volume of units sold in that market. In this study this criterion shows the extent of work for each contractor and expressed as a company's client number (only in Vilnius) divided by the total number of clients for all companies (also only in Vilnius):

$M_{C}=\frac{C_{n}}{\sum_{n=1}^{r} C_{n}}$,

where: $M_{C}$ - market share for each contractor; $C_{n}-$ number of clients of company $n ; \sum_{n=1}^{r} C_{n}$ - the total number of clients for $r$ companies; $R$ - total number of maintenance contractors involved in research (in our case $r=15$ ).

Number of projects per executive - this criterion evaluates the effectiveness of contractor's personnel (labour productivity). Higher value means effective organization of work, presence of special procedures, tools, instructions, forms and other means for work coordination and performance in time ensuring proper quality.

Value is calculated according to the formula:

$N_{p e}=\frac{N_{p}}{N_{e}}$,

where: $N_{p}$ - number of projects implemented per year; $N_{e}-$ average number of employees directly involved in projects being implemented per year.

Evaluation of management $\operatorname{cost}\left(C_{\min } / C_{\mathrm{p}}\right)-$ this criterion evaluates the cost competitiveness of contractor (could be noted as $C_{\mathrm{ec}}$ ). $C_{\text {min }}$ is minimal cost in all offerings, $C_{\mathrm{p}}$ (could be noted anew as $C_{\mathrm{c}}-$ cost of contractor) is the cost offered by contractor:

$C_{e c}=\frac{C_{\min }}{C_{c}}$. 


\section{Appendix B}

MOORA: square root method (1a until 1c) and MOORA reference point theory (1d-1e)

\begin{tabular}{|c|c|c|c|c|c|c|c|c|c|}
\hline \multicolumn{10}{|c|}{ objectives for Lithuanian cor } \\
\hline \multicolumn{10}{|c|}{ 1a-Matrix of Responses of Alternatives on Objectives: $\left(x_{i j}\right)$} \\
\hline & 1 & 2 & 3 & 4 & 5 & 6 & 7 & 8 & 9 \\
\hline & $\max$ & $\max$ & $\max$ & $\max$ & $\min$ & $\min$ & $\min$ & $\min$ & $\min$ \\
\hline$a_{1}$ & 12 & 11.75 & 4.6 & 0.83 & 0.064 & 0.11 & 0.18 & 0.31 & 0.67 \\
\hline$a_{2}$ & 3 & 0.39 & 0.33 & 0.885 & 0.06 & 0.14 & 0.37 & 0.12 & 0.5 \\
\hline$a_{3}$ & 12 & 5.25 & 1.47 & 0.935 & 0.057 & 0.11 & 0.18 & 0.15 & 0.69 \\
\hline$a_{4}$ & 12 & 7.09 & 2.78 & 0.912 & 0.058 & 0.12 & 0.09 & 0.15 & 0.57 \\
\hline$a_{5}$ & 12 & 5.56 & 1.39 & 0.912 & 0.058 & 0.1 & 0.18 & 0.2 & 0.45 \\
\hline$a_{6}$ & 13 & 26.62 & 5.67 & 0.746 & 0.071 & 0.3 & 0.18 & 0.26 & 0.82 \\
\hline$a_{7}$ & 5 & 2.82 & 1.2 & 0.483 & 0.11 & 0.14 & 0.18 & 0.12 & 0.55 \\
\hline$a_{8}$ & 11 & 9.48 & 3.03 & 0.916 & 0.058 & 0.18 & 0.37 & 0.19 & 0.61 \\
\hline$a_{9}$ & 11 & 2.23 & 0.76 & 1 & 0.053 & 0.14 & 0.16 & 0.23 & 0.8 \\
\hline$a_{10}$ & 11 & 13.47 & 9.05 & 0.746 & 0.071 & 0.26 & 0.29 & 0.23 & 0.73 \\
\hline$a_{11}$ & 4 & 4.7 & 1.5 & 0.443 & 0.12 & 0.2 & 0.09 & 0.2 & 0.81 \\
\hline$a_{12}$ & 12 & 2.35 & 0.86 & 0.746 & 0.071 & 0.28 & 0.18 & 0.28 & 0.73 \\
\hline$a_{13}$ & 8 & 5.6 & 3.25 & 0.681 & 0.078 & 0.2 & 0.18 & 0.3 & 0.76 \\
\hline$a_{14}$ & 11 & 2.66 & 1.7 & 0.948 & 0.056 & 0.14 & 0.18 & 0.12 & 0.5 \\
\hline$a_{15}$ & 3 & 0.04 & 0.03 & 0.531 & 0.12 & 0.14 & 0.09 & 0.21 & 0.56 \\
\hline \multicolumn{10}{|c|}{$1 b-$ Sum of squares and their square roots } \\
\hline$a_{1}$ & 0.4489 & 144 & 138.0625 & 21.16 & 0.6889 & 0.0041 & 0.0121 & 0.0324 & 0.0961 \\
\hline$a_{2}$ & 0.25 & 9 & 0.1521 & 0.1089 & 0.7832 & 0.0036 & 0.0196 & 0.1369 & 0.0144 \\
\hline$a_{3}$ & 0.4761 & 144 & 27.5625 & 2.1609 & 0.8742 & 0.0033 & 0.0121 & 0.0324 & 0.0225 \\
\hline$a_{4}$ & 0.3249 & 144 & 50.41 & 7.7284 & 0.81 & 0.0036 & 0.0144 & 0.01 & 0.0225 \\
\hline$a_{5}$ & 0.2025 & 144 & 30.9136 & 1.9321 & 0.81 & 0.0034 & 0.01 & 0.0324 & 0.04 \\
\hline$a_{6}$ & 0.6724 & 169 & 708.6244 & 32.1489 & 0.5565 & 0.0050 & 0.09 & 0.0324 & 0.0676 \\
\hline$a_{7}$ & 0.3025 & 25 & 7.9524 & 1.44 & 0.2333 & 0.0121 & 0.0196 & 0.0324 & 0.0144 \\
\hline$a_{8}$ & 0.3721 & 121 & 89.8704 & 9.1809 & 0.8390 & 0.0034 & 0.0324 & 0.1369 & 0.0361 \\
\hline$a_{9}$ & 0.64 & 121 & 4.9729 & 0.64 & 1 & 0.0028 & 0.0196 & 0.0256 & 0.0529 \\
\hline$a_{10}$ & 0.49 & 121 & 182.25 & 81.9025 & 0.5625 & 0.0049 & 0.0676 & 0.0841 & 0.04 \\
\hline$a_{11}$ & 0.6561 & 16 & 22.09 & 2.25 & 0.1962 & 0.0144 & 0.04 & 0.0081 & 0.04 \\
\hline$a_{12}$ & 0.5329 & 144 & 5.5225 & 0.7396 & 0.5565 & 0.0050 & 0.0784 & 0.0324 & 0.0784 \\
\hline$a_{13}$ & 0.5776 & 64 & 31.36 & 10.5625 & 0.4638 & 0.0061 & 0.04 & 0.0324 & 0.09 \\
\hline$a_{14}$ & 0.25 & 121 & 7.0756 & 2.89 & 0.8987 & 0.0031 & 0.0196 & 0.0324 & 0.0144 \\
\hline$a_{15}$ & 0.3136 & 9 & 0.0016 & 0.0009 & 0.2820 & 0.0144 & 0.0196 & 0.0081 & 0.0441 \\
\hline$\Sigma$ & 6.5096 & 1496 & 1306.8205 & 174.8456 & 9.5549 & 0.0892 & 0.4950 & 0.6689 & 0.6734 \\
\hline root & 2.5514 & 38.6782 & 36.1500 & 13.2229 & 3.0911 & 0.2986 & 0.7036 & 0.8177 & 0.8206 \\
\hline
\end{tabular}

1c-Objectives divided by their square roots and MOORA *

\begin{tabular}{lllllllllllll}
\hline $\boldsymbol{a}_{\boldsymbol{1}}$ & 0.2626 & 0.3102 & 0.3250 & 0.3480 & 0.2690 & 0.2143 & 0.1563 & 0.2201 & 0.3778 & 0.0206 & 1.9541 & $\mathbf{4}$ \\
\hline $\boldsymbol{a}_{\boldsymbol{2}}$ & 0.1960 & 0.0776 & 0.0108 & 0.0250 & 0.2863 & 0.2009 & 0.1990 & 0.4524 & 0.1462 & -0.7949 & 1.1386 & $\mathbf{1 2}$ \\
\hline $\boldsymbol{a}_{\mathbf{3}}$ & 0.2704 & 0.3102 & 0.1452 & 0.1112 & 0.3025 & 0.1907 & 0.1563 & 0.2201 & 0.1828 & -0.1514 & 1.7821 & $\mathbf{6}$ \\
\hline $\boldsymbol{a}_{\boldsymbol{4}}$ & 0.2234 & 0.3102 & 0.1964 & 0.2102 & 0.2912 & 0.2009 & 0.1706 & 0.1223 & 0.1828 & 0.1081 & 2.0416 & $\mathbf{3}$ \\
\hline $\boldsymbol{a}_{\boldsymbol{5}}$ & 0.1764 & 0.3102 & 0.1538 & 0.1051 & 0.2912 & 0.1942 & 0.1421 & 0.2201 & 0.2437 & -0.1162 & 1.8173 & $\mathbf{5}$ \\
\hline $\boldsymbol{a}_{\boldsymbol{6}}$ & 0.3214 & 0.3361 & 0.7364 & 0.4288 & 0.2413 & 0.2377 & 0.4264 & 0.2201 & 0.3168 & 0.2202 & 2.1537 & $\mathbf{1}$ \\
\hline $\boldsymbol{a}_{\boldsymbol{7}}$ & 0.2156 & 0.1293 & 0.0780 & 0.0908 & 0.1562 & 0.3683 & 0.1990 & 0.2201 & 0.1462 & -0.6949 & 1.2386 & $\mathbf{1 1}$ \\
\hline $\boldsymbol{a}_{\boldsymbol{8}}$ & 0.2391 & 0.2844 & 0.2622 & 0.2291 & 0.2963 & 0.1942 & 0.2558 & 0.4524 & 0.2315 & -0.3010 & 1.6326 & $\mathbf{8}$ \\
\hline $\boldsymbol{a}_{\boldsymbol{9}}$ & 0.3136 & 0.2844 & 0.0617 & 0.0605 & 0.3235 & 0.1775 & 0.1990 & 0.1956 & 0.2803 & -0.4358 & 1.4977 & $\mathbf{9}$ \\
\hline $\boldsymbol{a}_{\boldsymbol{1 0}}$ & 0.2744 & 0.2844 & 0.3734 & 0.6844 & 0.2426 & 0.2344 & 0.3695 & 0.3546 & 0.2437 & 0.1083 & 2.0418 & $\mathbf{2}$ \\
\hline $\boldsymbol{a}_{11}$ & 0.3175 & 0.1034 & 0.1300 & 0.1134 & 0.1433 & 0.4018 & 0.2843 & 0.1100 & 0.2437 & -0.8671 & 1.0664 & $\mathbf{1 4}$ \\
\hline $\boldsymbol{a}_{\boldsymbol{1 2}}$ & 0.2861 & 0.3102 & 0.0650 & 0.0650 & 0.2413 & 0.2377 & 0.3980 & 0.2201 & 0.3412 & -0.8015 & 1.1320 & $\mathbf{1 3}$ \\
\hline $\boldsymbol{a}_{13}$ & 0.2979 & 0.2068 & 0.1549 & 0.2458 & 0.2203 & 0.2612 & 0.2843 & 0.2201 & 0.3656 & -0.6012 & 1.3324 & $\mathbf{1 0}$ \\
\hline $\boldsymbol{a}_{14}$ & 0.1959 & 0.2844 & 0.0736 & 0.1286 & 0.3067 & 0.1875 & 0.1990 & 0.2201 & 0.1462 & -0.1556 & 1.7780 & $\mathbf{7}$ \\
\hline $\boldsymbol{a}_{15}$ & 0.2195 & 0.0776 & 0.0011 & 0.0023 & 0.1718 & 0.4018 & 0.1990 & 0.1100 & 0.2559 & -0.9335 & 1.0000 & $\mathbf{1 5}$ \\
\hline
\end{tabular}

* The nature of the construction industry involves that the total number of the minima is mostly larger than the total number of the maxima with very often negative sums as a result, which is the case here. Therefore, to make the ranking more comprehensive, the supplement to make the smallest sum, here for $\mathrm{a}_{15}$, equal to one, is added to all the sums. 


\begin{tabular}{|c|c|c|c|c|c|c|c|c|c|c|c|}
\hline \multicolumn{12}{|c|}{ Table 1 - MOORA applied on 9 objectives for Lithuanian contractors. Reference Point Part } \\
\hline \multicolumn{12}{|c|}{$1 d$-Reference Point Theory with Ratios: co-ordinates of the reference point equal to the maximal objective values } \\
\hline$r_{i}$ & 0.1764 & 0.3361 & 0.7364 & 0.6844 & 0.3235 & 0.1775 & 0.1421 & 0.1100 & 0.1462 & & \\
\hline \multicolumn{10}{|c|}{ 1e-Reference Point Theory: Deviations from the reference point } & max. & rank min. \\
\hline$a_{1}$ & 0.0862 & 0.0258 & 0.4113 & 0.3365 & 0.0550 & 0.0368 & 0.0142 & 0.1100 & 0.2315 & 0.4113 & 3 \\
\hline$a_{2}$ & 0.0196 & 0.2585 & 0.7256 & 0.6595 & 0.0372 & 0.0234 & 0.0569 & 0.3424 & 0.0000 & 0.7256 & 14 \\
\hline$a_{3}$ & 0.0941 & 0.0258 & 0.5911 & 0.5732 & 0.0210 & 0.0134 & 0.0142 & 0.1100 & 0.0366 & 0.5911 & 8 \\
\hline$a_{4}$ & 0.047 & 0.0258 & 0.5400 & 0.4742 & 0.0324 & 0.023 & 0.028 & 0.012 & 0.037 & 0.5400 & 5 \\
\hline$a_{5}$ & 0.0000 & 0.0258 & 0.5826 & 0.5793 & 0.0324 & 0.0167 & 0.0000 & 0.1100 & 0.0975 & 0.5826 & 7 \\
\hline$a_{6}$ & 0.1450 & 0 & 0 & 0.2556 & 0.0822 & 0.0603 & 0.2843 & 0.1100 & 0.1706 & 0.2843 & 1 \\
\hline$a_{7}$ & 0.0392 & 0.2068 & 0.6584 & 0.5937 & 0.1672 & 0.1909 & 0.0569 & 0.1100 & 0 & 0.6584 & 10 \\
\hline$a_{8}$ & 0.063 & 0.0517 & 0.4741 & 0.4553 & 0.0272 & 0.017 & 0.114 & 0.342 & 0.085 & 0.4741 & 4 \\
\hline$a_{9}$ & 0.1372 & 0.0517 & 0.6747 & 0.6239 & 0 & 0.0000 & 0.0569 & 0.0856 & 0.1340 & 0.6747 & 13 \\
\hline$a_{10}$ & 0.0980 & 0.0517 & 0.3629 & 0 & 0.0809 & 0.0569 & 0.2274 & 0.2445 & 0.0975 & 0.3629 & 2 \\
\hline$a_{11}$ & 0.1411 & 0.2327 & 0.6064 & 0.5710 & 0.1802 & 0.2244 & 0.1421 & 0.0000 & 0.0975 & 0.6064 & 9 \\
\hline$a_{12}$ & 0.1097 & 0.0258 & 0.6714 & 0.6194 & 0.0822 & 0.0603 & 0.2558 & 0.1100 & 0.1950 & 0.6714 & 12 \\
\hline$a_{13}$ & 0.1215 & 0.1293 & 0.5815 & 0.4386 & 0.1032 & 0.0837 & 0.1421 & 0.1100 & 0.2193 & 0.5815 & 6 \\
\hline$a_{14}$ & 0.0196 & 0.0517 & 0.6628 & 0.5558 & 0.0168 & 0.0100 & 0.0569 & 0.1100 & 0.0000 & 0.6628 & 11 \\
\hline$a_{15}$ & 0.0431 & 0.2585 & 0.7353 & 0.6821 & 0.1517 & 0.2244 & 0.0569 & 0.0000 & 0.1097 & 0.7353 & 15 \\
\hline
\end{tabular}

\section{References}

Arrow, K. J. 1974. General economic equilibrium: purpose, analytic techniques, collective choice, American Economic Review 64(3): 253-272.

Banaitiene, N.; Banaitis, A. 2006. Analysis of criteria for contractors“ evaluation, Technological and Economic Development of Economy 12(4): 276-282.

Brauers, W. K. 2008. Multi-objective decision making by reference point theory for a wellbeing economy, Operations Research International Journal 8: 89-104.

Brauers, W. K. 2007. What is meant by normalization in Decision Making? International Journal of Management and Decision Making 8(5/6): 445-460.

Brauers, W. K. 2004. Optimization methods for a stakeholder society. Boston: Kluwer Academic Publishers.

Brauers, W. K. 2002. The multiplicative representation for multiple objective optimization with an application for arms procurement, Naval Research Logistics 49: 327-340.

Brauers, W. K. 1999. An optimal economic policy for Belgium and its regions (in Dutch), Documentatieblad. Department of Finance of the Belgian Government, Brussels.

Brauers, W. K. 1997a. The multiplicative representation in multiple objective utility theory, Working Paper 97/06, Department of Applied Economics, University of Antwerp.

Brauers, W. K. 1977b. Multiple criteria decision making and the input-output model for national defense. Belgian Department of National Defense, Brussels.

Brauers, W. K.; Zavadskas, E. K. 2006. The MOORA method and its application to privatization in a transition economy, Control and Cybernetics 35(2): 445-469.

Bridgman, P. W. 1922. Dimensional analysis. New Haven, CT: Yale University Press (new ed. 1963).
Churchman, C. W.; Ackoff, R. L.; Arnoff, E. L. 1957. Introduction to operations research. New York: Wiley.

Churchman, C. W.; Ackoff, R. L. 1954. An approximate measure of value, Operations Research 2: 172-180.

Colson, G. and Bruyn, C. D. 1989. Models and methods in multiple criteria decision making. New York: Pergamon.

Dikmen, I.; Birgonul, M. T.; Gur, A. K. 2007. A case-based decision support tool for bid mark-up estimation of international construction projects, Automation in Construction 17(1): 30-44.

Ginevičius, R. and Korsakienè, R. 2005. Exploration of strategy: objectives, competencies and competitive advantage, Journal of Business Economics and Management 6(1): 13-22.

Ginevičius, R. and Vaitkūnaitè, V. 2006. Analysis of organizational culture dimensions impacting performance, Journal of Business Economics and Management 7(4): 201-211.

Hatush, Z. and Skitmore, R. M. 1997. Assessment and evaluation of contractor data against client goals using PERT approach, Construction Management and Economics 15(4): 327-340.

Hatush, Z. and Skitmore, R. M. 1998. Contractor selection using multi-criteria utility theory: an additive model, Building and Environment 33(2/3): 105-115.

Holmes, J. C. 1971. An ordinal method of evaluation, Urban Studies 9: 179-191.

Hwang, C. L. and Yoon, K. S. 1981. Multiple attribute decision making/methods and applications. Berlin, Heidelberg, New York: Springer-Verlag.

Jaselskis, E. J.; Russell, J. S. 1992. Risk analysis approach to selection of contractor evaluation method, ASCE Journal of Construction Engineering and Management 118(4): 814-821. 
Karlin, S. and Studden, W. J. 1966. Tchebycheff systems: with applications in analysis and statistics. Interscience Publishers, New York.

Keeney, R. L. and Raiffa, H. 1993. Decisions with multiple objectives, preferences and value tradeoffs. Cambridge [England]; New York, NY, USA: Cambridge University Press.

Kendall, M. G. 1948. Rank correlation methods. London: Charles Griffin \& Company, Ltd.

Kersuliene, V. 2007. Possibilities of clients and contractor's disputes settlement at the pretrial stage, Technological and Economic Development of Economy 13(2): 139-143.

Lee, S. M. 1972. Goal programming for decision analysis. Philadelphia: Auerbach Publishers.

Lin, C. T. and Wu, C. R. 2007. Editorial: qualitative and quantitative methods aimed at technology management, International Journal of Technology Management (IJTM) 40(1/2/3): 1-6.

Miller, D. W. and Starr, M. K. 1969. Executive decisions and operations research, 2nd edition, Englewood Cliffs, N. J.: Prentice-Hall Inc., 237-239.

Minkowsky, H. 1896. Geometrie der Zahlen. Teubner, Leipzig. Mitkus, S. and Trinkuniene, E. 2007. Analysis of criteria system model for construction contract evaluation, Technological and Economic Development of Economy 13 (3): 244-252.

Mitkus, S. and Trinkūnienė, E. 2006. Models of indicator systems of construction contraction agreements, Journal of Civil Engineering and Management 12(4): 327-335.

Ng, S. T.; Skitmore, R. M.; Smith, N. J. 1999. Decisionmakers perceptions in the formulation of prequalification criteria, Engineering Construction \& Architectural Management 6(2): 155-165.

Ng, S. T. and Wan, W. Y. 2005. Appraisal of subcontractor performance - criteria and their importance, in A. S. Kazi (eds.). Proceedings of CIB2005-Advancing Facilities Management and Construction through Innovation, Finlandia Hall, Helsinki, Finland, 305-314.

Roy, B.; Benayoun, R.; Sussman, B. 1966. ELECTRE, Société d'Economie et de Mathématique Appliquées.

Saaty, T. L. 1988. The analytic hierarchy process. New York: McGraw-Hill.

Sage, A. P. 1977. Methodology for large scale systems. New York: McGraw-Hill.

Schärlig, A. 1985. Décider sur plusieurs critères. Lausanne Presses Polytechniques Romandes.

Schieg, M. 2006. Risk management in construction project management, Journal of Business Economics and Management 7(2): 77-83.

Shiau, Y. C.; Tsai, T. P.; Wang W. C.; Huang, M. L. 2002. Use questionnaire and AHP techniques to develop subcontractor selection system, in International Symposium on Automation and Robotics in Construction, 19th (ISARC) Proceedings, National Institute of Standards and Technology, Gaithersburg, Maryland , 35-40.

Skibniewski, M. J. and Chan, L. C. 1992. Evaluation of advanced construction technology with AHP method, Journal of Construction Engineering and Management 118(3): 577-593.

Spearman, C. 1904. The proof and measurement of association between two things, American Journal of Psychology 15: 88-93.

Spearman, C. 1906. A footrule for measuring correlation, British Journal of Psychology 2: 89-108.

Spearman, C. 1910. Correlation calculated from faulty data, British Journal of Psychology 3: 271-295.

Topcu, Y. I. 2004. A decision model proposal for construction contractor selection in Turkey, Building and Environment 39: 469-481.

Tserng, H. P.; Lin, P. H. 2002. An accelerated subcontracting and procuring model for construction projects, Automation in Construction 11(1): 105-125.

Turskis, Z.; Zavadskas, E. K; Zagorskas, J. 2006. Sustainable city compactness evaluation on the basis of GIS and Bayes rule, International Journal of Strategic Property Management 10: 185-207.

Zagorskas, J. and Turskis, Z. 2006. Multi-attribute model for estimation of retail centres influence on the city structure. Kaunas city case study, Technological and Economic Development of Economy 12(4): 347-352.

Zavadskas, E. K. and Kaklauskas, A. 1996. Determination of an efficient contractor by using the new method of multicriteria assessment, in International Symposium for the Organisation and Management of Construction. Shaping Theory and Practice. Vol. 2: Managing the Construction Project and Managing Risk. Ed. by Langford, D. A. and Retik, A. CIB W 65. London, Weinheim, New York, Tokyo, Melbourne, Madras. London: E and FN SPON 2: 94-104.

Zavadskas, E. K. and Vilutienè, T. 2006. A multiple criteria evaluation of multi-family apartment block's maintenance contractors: I-Model for maintenance contractor evaluation and the determination of its selection criteria, Building and Environment 41(5): 621-632.

Zavadskas, E. K. and Kaklauskas, A. 2007. Mehrzielselektion für Entscheidungen im Bauwesen. Fraunhofer IRB Verlag.

Zimmermann, H. J. 1978. Fuzzy Programming and Linear Programming with several Objective Functions, Journal of Fuzzy Sets and Systems 1: 45-55.

Zou, P. X. W.; Zhang, G.; Wang, J. 2007. Understanding the key risks in construction projects in China, International Journal of Project Management 25(6): 601-614. 